International Journal of English Literature and Social Sciences
Vol-6, Issue-1; Jan-Feb, 2021

\title{
Mother Tongue Based Language Education in Philippines And Cambodia: A Comparative Study
}

\author{
Pinky Larcelle D. Lang-ay, Jessie Grace M. Sannadan
}

Kalinga State University, Tabuk City, Kalinga, Philippines

Received: 12 Oct 2020; Received in revised form: 19 Jan 2021; Accepted: 09 Feb 2021; Available online: 25 Feb 2021

(C2021 The Author(s). Published by Infogain Publication. This is an open access article under the CC BY license

(https://creativecommons.org/licenses/by/4.0/).

\begin{abstract}
The implementation of Mother Tongue-Based Multilingual Education addresses numerous educational issues in the Philippines and Cambodia by recognizing a child's mother tongue, culture, and context as the foundation of learning. The study used literature juxtaposition and qualitative meta-analysis to conduct a rigorous secondary qualitative analysis of primary qualitative findings. This is to provide a more comprehensive description of the implementation of MTB-MLE in both countries and its perceived effects on the indigenous communities. The study determined that most mother tongue-based education in both countries occur in the non-formal sector, particularly at the preschool or adult literacy classes. Most programs are run by non-governmental actors, such as local and international NGOs and other civil society actors. It further concludes that this learning initiative helped the marginalized minorities through supporting the use of their mother tongue and helping them make sense of the words and the world they are in. This learning initiative would encourage students to achieve more and would allow them to relate their everyday reality to reality nationally, internationally, and globally.
\end{abstract}

Keywords- Mother Tongue-Based Education, Multilingual Education, Comparative Study, Philippines, Cambodia.

\section{INTRODUCTION}

Following the International Human Rights Regime, the education of Indigenous peoples is a priority concern. For the Indigenous to enact their Rights fully, develop their skills, capacities, potentials, and to realize other aspects of Indigenous Rights, education is fundamental. According to John Dewey, an American Philosopher, Education is not a preparation for life; instead, it is the living. Education is the process of living through a continuous reconstruction of experiences. It is the development of all those capacities in the individual, which will enable him to control his environment and fulfill his possibilities". Education of Indigenous Peoples is essential, a fundamental human right, empowerment and a precondition for a continuous reconstruction that will ensure their individual and collective development, enabling them to control their environment, realize their aspiration in the self-determination of pursuing economic, social, and cultural development. Achieving the right to education is often very involved in indigenous people's practice with state control and the mainstream educational system.

The United Nations approved a Declaration of the Rights of Indigenous People on September 13, 2007. Only Australia, Canada, New Zealand, and the United States of America declined to ratify this declaration. However, since then, all four of these countries have reversed their positions. Article 13-1 of the declaration states: "Indigenous peoples have the right to revitalize, use, develop and transmit to future generations their histories, languages, oral traditions, philosophies, writing systems and literature, and designate and retain their names, communities, places, and persons." On the other hand, article 14-1 declares: "Indigenous peoples have the right to establish and control their educational systems and institutions providing education in their languages, in a manner appropriate to their cultural methods of teaching and learning" [1] 
According to Amnesty International, there are 370 million indigenous peoples clustered to 5000 various groups. Seventy percent are in Asia. Though the concrete and universal definition of "indigenous" is uncertain, there is an understanding that indigenous people differ from the dominant groups in society in that they hold "a historical continuity with pre-invasion and pre-colonial societies that developed on their territories. They have a unique social, economic, and political system and carry a firmness to preserve their culture and conserve their ancestral environments.

Nevertheless, indigenous peoples face varied problems. They are repeatedly displaced from their lands, are relegated as second-class members of society, and are alienated from the spread of capitalism. These unpleasant realities continue to happen. These upsetting actualities can be primarily credited to the denial of access to valuable education for indigenous societies.

The scheme of education programs must weigh up the unique requirements of these groups. Indigenous students cannot succeed well in conventional education approaches that do not take into consideration indigenous culture. Therefore, due to indigenous peoples' diversity, a scheme that undertakes universality will be ill-fitting and tragic for them. A tailored model that encourages human rights, gender sensitivity, and especially indigenous perspectives, innovations, and practices in an environment that replicates traditional learning methods might affect the proliferation of competitive indigenous education. The United Nations Inter-Agency Support Group emphasizes that the "most effective way...is to work in a communitybased, bottom-up manner to ensure that infrastructure, pedagogical materials, and curricula meet the sometimes unique needs of indigenous teachers, learners and their communities" [2]

"Language is vital to communication. It can offer links to new opportunities or build fences to equality. It links and disengages. It generates harmony and can cause struggle. Language is many things, but it is seldom modest" [3].

Language is a crucial part of a person's identity and culture - it is the cognition that makes us human. Approximately 6,900 languages are spoken throughout the world, depending on different estimates and definitions, adding to the rich linguistic, ethnic, and cultural diversity. Many of the languages used by linguistic minorities are only in spoken form, and some are in severe danger of disappearing altogether. According to recent studies, half of the world's languages will be extinct by the end of this century ${ }^{[4]}$
Since the last decade, education has triumphed in many developing countries, where millions of children have gained the opportunity to go to school. Although much has been accomplished, obstacles and challenges remain in achieving quality education for all children worldwide. Language is undoubtedly one of the essential factors in the learning process, and the language factor emerges strongly as one of the most salient determinants of quality in education. Unfortunately, most linguistic minorities go to school every day with a significant burden because they do not speak or understand school instruction. For many children, being forced to drop from school is not due to physical or monetary barriers, but to the decision to be taught in a language that they can't understand ${ }^{[5]}$.

In the longer term, the most vulnerable people will remain low and excluded if their right to education is not fulfilled because of the language policy in a society where they already face exclusion and marginalization. The loss of linguistic diversity can be equated with the loss of humanity's heritage. Language is always embedded in culture, and when people's linguistic rights are not respected, it adversely affects their cultural identity and violates their right to practice their own culture. Language rights should be embraced, not least because they promote diversity, tolerance, and non-discrimination worldwide ${ }^{[6,}$ 7].

\section{CONCEPTUAL BACKGROUND}

\section{Mother Tongue Based-Multilingual Education (MTB- MLE)}

Education is perceived as one of the most important ways for people to move out of poverty. A robust primary education is a core, but many linguistic minority children struggle at school when they are required to learn in a foreign language. School systems that do not use learners' languages or respect their cultures make it extremely difficult for children to stay in school and learn. Multiple studies have proved that children learn better in their Language ${ }^{[8]}[9][10]$.

In Southeast Asia, many children are taught in languages that are not spoken in their immediate community. The area has rich linguistic diversity with more than 1,200 languages spoken in the region, but colonization has also left its mark on many countries' education policies. Most Southeast Asian countries have prioritized the national and official languages in their education systems to build a unified nation [11]. However, according to Kosonen and Young [12], children who cannot learn in their mother tongue are also over-represented. Such language policies have been proven to cause low- 
quality education and only benefit a tiny and elite minority, mostly urban areas. Moreover, members of this minority can also speak national or international languages. Hence, most of the linguistic minorities who live in rural areas have not enjoyed education benefits.

According to Pinnocks and Vijayakumar ${ }^{[7]}$, literacy becomes a particular challenge when children do not know the language used to teach reading and writing. Literacy can be defined as the method of linking the ideas associated with spoken words to written text. If a child does not understand a word's meaning - used in a foreign language - reading and writing are simply based on rote. Children only learn to copy and recite texts from blackboards and books without developing the ability to produce new writing by themselves. What is most disconcerting is that children never become fully literate if they do not already know the Language in which reading and writing are taught well enough. Such language policies have not been successful and have resulted in low academic achievement, grade repetition, and dropping out. It is no surprise that many schools in developing countries where such policies are applied are ineffective, and students have low academic achievements. In many cases, the school remains an unfamiliar and sometimes frightening place for children from non-dominant language groups [13].

The best way to overcome these trials is through MTB MLE, which aims to address this educational issue by recognizing a child's mother tongue, culture, and context as the foundation of learning. In MTB MLE programs, children learn in their mother tongue and learn the official Language or other L2 subjects. As learners gain competence in speaking, reading, and writing in the National Language, teachers begin using it for teaching. The best MTB MLE programs encourage learners to use both languages to communicate and learn throughout primary school ${ }^{[5] .}$

MTB MLE functions best when a child's mother tongue is used as the primary language of teaching, beginning in the first years of school and continuing for as long as possible. The mother tongue is considered the learner's first Language (L1), which remains the critical Language of education. For linguistic minorities, acquiring proficiency in national and international languages is also crucial to communicate with broader society, gain access to public services, and take advantage of further study and employment opportunities. Starting in the Language, they recognize best allows children to build a strong foundation, which duly enables them to make a significant shift into other national or international languages - known as a second language(s) (L2) - which added to the curriculum later ${ }^{[14]}$.Pinnock and Vijayakumar ${ }^{[7]}$ argue that the L2 should not become the primary Language of teaching and learn for at least six years. A third language (L3) can be added at a slightly later stage when children have already developed their linguistic and cognitive skills through their mother tongue.

The use of MTB MLE has multiple benefits. Using their mother tongue helps children adjust to the new school environment, adding to them learn more effectively and have more self-confidence. Thus, it makes the transition from home to school more natural. When children can use their Language in school, they achieve better grades because it improves learning quality and is unlikely to drop out. The most productive focus for

MTB MLE is to embed culturally relevant education in a comprehensive approach; thus, the needs and interests of linguistic minorities are compatible with the curriculum, and children learn more efficiently. Moreover, parents become more favorably disposed to send their children to school. MTB MLE has facilitated considerable advances in the psychosocial sphere. When the same Language is used at home and in the classroom, it engenders greater confidence among children. In bilingual schools, children are happier to learn, are more expressive, and have higher self-esteem than those who are not in bilingual schools [6]. According to Benson [15], better communication and interaction encourage students to be more active and participate more readily in class.

Moreover, family members play a vital role in non-formal education. The use of the mother tongue helps to promote better understanding and communication between home and school. In the same vein, parents and other family members can support the children's education.

MLE education has successfully reduced the educational gap between boys and girls since girls have been reported as having fewer opportunities than boys to complete primary school ${ }^{[6]}$. According to UNESCO ${ }^{[16]}$, parents may be more confident about placing their girls in schools where the Language of teaching is their mother tongue, as it reflects a familiar culture and set of values. Most commonly, teachers in MTB MLE schools are from their communities, and parents have more confidence in teachers that they know. Furthermore, Benson [17] argues that working near home encourages female students from linguistic minorities to attend teacher training courses and become teachers in their communities where MLE schools exist. In this sense, they also become important role models.

Moreover, MTB MLE programs are costeffective. According to a cost-benefit analysis of MTB MLE, their implementation costs more to set up. Still, the longer-term leads to reduced repetition and dropout rates, 
resulting in significant cost savings $\left.{ }^{[7}\right]$. Indeed, UNESCO [16] has urged society to contemplate the cost of an education system that fails most learners who do not speak the Language of instruction.

\section{Demographic Context}

\section{Philippines}

The Philippines is an abode to around one hundred ten indigenous people's societies numbering between fifteen to twenty million. They are located in various areas of the country, with more than sixty percent in the Mindanao island, around thirty percent in Luzon island, and less than ten percent in the Visayas region's islands.

Indigenous peoples (IPs) have always comprised a significant percentage of the Filipino population. In 1995, the National Commission on Indigenous Peoples (NCIP) estimated the IP population throughout the country at 12 million, which was equivalent to almost $20 \%$ of the total Filipino population in that period. In a 2000 census (Census on Housing and Population, 2000), the reported IP population reached only 6.3 million. Even with the substantial decline in numbers, the sector still constituted $8 \%$ of the rapidly growing (76.5 million) Filipino population (National Statistics Office Census, 2000).

It is significant to note that IPs are present in all the Philippine Administrative Regions, except Region VIII (1996 Accomplishment Report of the Office of the National Cultural Communities, as cited in ADB Indigenous Peoples Development Framework). A majority of them (61\%) found in Mindanao, a third (33\%) resides in Luzon, and the remaining few $(6 \%)$ live in the Visayas.

In Mindanao, IP settlements are scattered in Davao, Cotabato, Sultan Kudarat, Zamboanga, Maguindanao, Agusan del Sur, Agusan del Norte, Misamis Oriental, and Bukidnon.

In Luzon, IP communities are concentrated in Cordillera, Bontoc, Sagada, Ifugao, and Southern Kalinga. A significant population can also be found in Cagayan Valley, Caraballo Range, Sierra Madre Range, Zambales Range, and the Island Groups of Mindoro, Negros, Panay, and Palawan.

Ethnicity varies in each region as distinguished by social, cultural, political, and linguistic features. Approximately 150 ethnic groups in the Philippines have been recorded by the Presidential Advisor for Indigenous Peoples Affairs, and 168 functional languages have been identified by the Summer Institute of Linguistics (Asian Development Bank).

In the province of Bukidnon, for example, there are seven major ethnolinguistic groups present. These are the Bukidnon, Higaonon, Matigsalug, Talaandig, Tigwahanon, and Umayamnen.

In the ARMM region, where close to $60 \%$ of the population is indigenous, the Asian Development Bank (ADB) identified 13 Islamized ethnolinguistic groups and 18 non-Muslim Lumad groups living in the area. The Islamized groups are the Badjao, Iranun, JamaMapun, Kalagan, Kalibugan, Maranao, Maguindanao, Molbog, Palawani, Samal, Sangil, Tausug, and Yakan. The nonIslamized groups, on the other hand, include the Bagobo, Mansaka, Mandaya, Subanen, B'laan, T'Boli, Tiruray, and Manobo. As a sector, IPs have a relatively young population. $41 \%$ of the total IP population surveyed in 2000 (Census on Housing and Population, 2000) belongs to the $0-14$ age bracket, while $56 \%$ belongs to the $15-64$ age group ${ }^{[18]}$.

\section{Cambodia}

Cambodia is a monarchy in South-East Asia with inhabitants of roughly 12 million. Ethnic Khmer, mostly Buddhist, composed closely to $90 \%$ of the population. The Language is Khmer, creating Cambodia, one of the linguistically slightest varied nations in the region. About 19 other languages are verbal in the state. City-dwelling Chinese, Cham, and Vietnamese reside along the waterways, consisting of the most significant minority clusters. In contrast, some ethnic minority groups, frequently branded "indigenous peoples" or "highlanders," are mainly situated in Cambodia's northeastern parts.

Based on the evaluation of the adult population's functional literacy levels in Cambodia, $36.3 \%$ of the people are entirely illiterate, $26.6 \%$ are semi-literate, and only $37.1 \%$ are functionally literate the sense that they can deal with both reading/writing and socioeconomic issues. If the data is divided into female/male rates, the statistics show that only $29.2 \%$ of the females are functionally literate, while the figure for men is $47.6 \%$. Literacy rates differ according to ethnicity, though there is insufficient data to contrast various ethnic groups.

It can be pointed out that many NGOs are working in Cambodia: international and national and local. These NGOs play an essential role in civic society and are instrumental in complementing government services in many areas due to inadequate government funding, competencies, and facilities. NGOs are at times in such a way that they may directly influence policy-making, which is a unique situation in South East Asia ${ }^{[19]}$.

\section{Official Language \\ Philippines}

The Philippines is an archipelago that can be found in the Pacific. It is rich in linguistic and cultural 
diversity. According to the Ethnologue, it is second only to Indonesia in Southeast Asia, as 186 languages are estimated to be spoken in the country ${ }^{[20]}$. Languages such as Bicol, Cebuano, Ilonggo, Ilocano, and Tagalog are spoken by millions of people and widely used as languages of wider communication in their respective areas. Most ethnolinguistic minorities are much smaller. Orthographies already exist in most languages, and more than 100 languages possess written materials ${ }^{[13]}$.

For the most significant part, this linguistic variety has not been reflected in governmental and educational policies. The existing constitution states both English and Filipino (Tagalog) to be the republic's official languages, as both spoken in Metro Manila, the nation's capital ${ }^{[21]}$.

Implementing English and Tagalog, the Philippines' official languages, is a good move, seeing it as a required language used to do business and trade in both the national and international arena. Still, these two languages' constitutional statements as official and the other languages as auxiliary take a discriminatory tone when looking at how it resonates in other policies and the public sphere ${ }^{[21]}$.

\section{Cambodia}

In the Kingdom of Cambodia, the Khmer are the dominant ethnolinguistic groups in terms of influence and population, as they comprise about 90 percent of the populace. Although there are 21 other languages spoken by the remaining ten percent, Cambodia is among the least linguistically diverse nations in Asia [21, 22]. Most ethnolinguistic minority groups in the country are small, apart from the Cham, Chinese, and Vietnamese, whose populations are hundreds of thousands ${ }^{[22-24]}$.

The Constitution of 1993 declared Khmer as the official Language and gives the Khmer script an official position (Constitution Finder, 2012). Until the late 1990s, Khmer was solely the Language of teaching education levels, though schools in some areas had also been teaching Chinese or Vietnamese as study subjects. L1based bilingual education programs in formal and nonformal education have been introduced by numerous international agencies and non-governmental organizations (NGOs) in close alliance with provincial education experts and local groups. Five non-dominant languages, specifically Brao, Bunong, Kavet, Krung, and Tampuan, have been presented as languages of teaching, and work is ongoing in three additional languages: Jarai, Kaco' and $\mathrm{Kui}^{[25-28]}$.

\section{Language in Education}

Philippines
According to the 1987 Constitution, the national Language is Filipino (based on Tagalog), and Filipino and English are the official languages. The Bilingual Education Policy of 1974, revised in 1987, states that English and Filipino are the languages of education and literacy's official languages. The constitution also gives regional languages a status as auxiliary languages in their respective areas. They can also be used to facilitate understanding of the curricula in the official languages of instruction. The goal of the bilingual policy is to create a population bilingual in the official languages. However, the majority of Filipinos do not speak either of these languages as their mother tongue. It assessed that only about a quarter of the population receives education. Filipino and English prominence means that most Filipinos study through languages other than those they speak at home ${ }^{[30]}$.

Regional and local languages have been used in government schools as "transitional languages" for initial instruction and early literacy up to primary Grade 3 . However, these activities have not been carried out on a large scale. Since the 1987 revised policy, regional nondominant languages have elevated to the role of auxiliary languages. However, this has typically meant that NDLs are used orally to explain the curriculum to students, rather than using them seriously as media of instruction. In some cases, Lubuagan, for example, when the learners' home language has been used as the Language of teaching, learning achievement has improved ${ }^{[31]}$. The use of NDLs varies, depending on the teachers and the availability of learning materials in those languages. Nevertheless, as most languages' orthographies are somewhat similar, many people literate in Filipino can often quite quickly transfer their literacy skills into their mother tongue ${ }^{[31,32] .}$

Non-dominant languages are used more widely in the non-formal sector. NGOs in non-formal education have accomplished much language development. Non-formal education programs using local languages are usually run by community organizations, NGOs, and churches, and are relatively small. Some non-formal education endeavors have close links with the formal system, although most non-formal education focuses on adult literacy. Arabic is also used in Qur' anic schools, mainly in the South of the country ${ }^{[32]}$.

In the Philippines, non-dominant languages are used in education, particularly in non-formal education, perhaps more widely than in other Southeast Asian countries. Still, Filipino and English continue as the main languages of instruction throughout the nation, even after recent debates over current policy and the importance of the learners' home language in education. 
Provided this legacy, the transformed DepEd has required to address the criticism of not providing an excellent adequate base for those desiring to continue a university education. To attain this, they pushed a bill through Congress that overhauls the former educational system. There are two primary components of the stated aim to modify Philippine schools' arrangement, which started in 2012 intensely.

The first is the additional years for secondary school. Preceding to 2012, there was a 10-year long education series. With this bill, the Philippines adopted a $\mathrm{K}-12$ cycle to guarantee that students are prepared to go to university after graduation from grade $12^{[33]}$.

The bill's second core component addresses the linguistic discernment in highlighting English education by employing Mother Tongue Based Multilingual Education (MTB-MLE). This model endorses the Language of teaching in the school district's mother tongue, rather than Filipino (Tagalog) or English. Nevertheless, these other languages will be imparted and incorporated into the curriculum progressively. Supporters of this approach point to pilot programs in the Philippines that have been fruitful in serving students gain full expertise in the mother tongue, the national language Filipino, and English.

There is also provision for this process from the United Nations (UN), in their "Education for All" program. The UN has come out in backing of the move, because their own goal is to improve education, with the belief that there needs to be a general recognition of linguistic minorities. By initially with the Language that one speaks at home, the gap in understanding can be bridged, and students can better learn the curriculum.

The foremost concern that many educators have with this law is the velocity with which the bill requires a change, making teachers feeling unprepared for the dramatic shift. The circumstance of 13 years of education for children, rather than 10 , calls an extended curriculum that educators cannot use. It makes some educators feel that they are imperfectly qualified for such a cycle. Rechelle Guzman, a fellow of the chamber of commerce in Pampanga, Philippines, expounded on the language training modification struggle. "There are no accessible modules and materials or books to upkeep our Mother tongue (Kapampangan) curriculum." Without the appropriate tools, the legislation's implementation is in danger of losing its effectiveness.

Besides, the meaning of "mother tongue" is an argumentative subject, as numerous parents teach their children English at home. "Mother tongue" is understood by some as the cultural Language, but others as the Language taught from birth, regardless of whether it is part of traditional heritage. Without an explicit agreement, resistance to the law and confusion within communities will remain ${ }^{[21]}$.

\section{Cambodia}

In the necessary education, the Language of instruction is Khmer. However, in university education, the situation is different; Khmer has not yet developed for many studies. Clayton (2006) mentions, "While the national language serves as the medium of education in many universities, its utility at this level is limited, particularly in terms of its technical precision."

Cambodians regained their freedom to learn and use the Chinese Language in 1993, more than 20 years after the Khmer Republic first enforced the language ban in 1970 and then carried out by subsequent regimes. Many schools have opened, and numerous students study at these schools. Clayton (2006) observes: "The skyrocketing enrollment in Chinese-language schools provides one illustration of how Cambodians have embraced this new freedom."

\section{OBJECTIVES}

1. To determine the present state of MTB-MLE implementation in the Philippines and Cambodia;

2. To identify the target learners/beneficiaries in both countries;

3.To examine the current condition in the two selected community-based learning areas in the Philippines and Cambodia; and

4.To determine the effects of the MTB-MLE

\section{SIGNIFICANCE OF THE STUDY}

The study will be used as basis information of the program and policymakers and implementers to enhance the Mother Tongue Based Education implementation in the Philippines and Cambodia.

\section{RESEARCH METHODOLOGY}

The researchers used Area Study Approach, a qualitative research design standard in Comparative Education. Under this approach, the researchers engaged themselves in a chosen country's educational practices besides their own, like Cambodia. In 2016, the researchers had the chance to visit Cambodia and learned about the country's education and culture. They engaged themselves in the country's educational practices and arrived at a body of generalizations on the implementation of the Mother Tongue Based Multilingual Education. 
In the first stage of their study, called the Descriptive Stage, the researchers made descriptions of the MTB-MLE implementation in the Philippines. This was followed by an intensive review of available literature on MTB-MLE in Cambodia. It is also called as the spot assessment. The next stage is the Interpretation Stage; the researchers collated and analyzed the data gathered from various sources to enable them to do justice in the implementation of Mother Tongue Based Education in Cambodia. The third stage is the Juxtaposition Stage. At this stage of the study, the researchers placed side by side the result obtained from the interpretation stage with the MTB-MLE of their own country (Philippines). And lastly, the Comparative Stage is where the researchers objectively compared and contrasted the MTB-MLE between the Philippines and Cambodia.

\section{RESULTS AND DISCUSSION}

\section{Child Birth Rites of the Kankanaeys}

\section{A. Implementation of the Mother Tongue Based- Multilingual Education (MTB-MLE)}

\section{Philippines}

In supporting the first Language, there is a need for respect and support the home language, planning base on the improvement of knowledge of the Language, producing an atmosphere to support natural language education, observing children talking, finding out what they recognize in utilizing Language, establishing a supportive setting, sympathetic and appreciating the home literacy and helping parents to understand the value of a strong first or home language ${ }^{[38]}$.

Local and international research shows that the learner's mother tongue usage at home is the most effective education medium. "It is the easiest way for learners to access the unaccustomed world of school learning. (Luistro)" Suppose the mother tongue usage will be rejected in favor of a new, unfamiliar language upon the children's entry into grade school. In that case, the students lose attention in their studies because there is discontinuation in the Language used at home and school. It will also be a loss of self-assurance as students since their culture and experiences are barred in classroom interactions ${ }^{[39]}$.

MTB-MLE helps students build a 'good bridge' when the teachers introduce other languages orally through meaningful and non-threatening activities. It presents writing and reads different languages by building on what they have learned through the oral teaching of Language and their foundation in the first language literacy and, finally, build eloquence and confidence in using the verbal and written Language for everyday communication academic learning ${ }^{[40]}$.

Language is one of the treasured gifts which have been conceded to children. The first Language is essential and builds the foundation for all later Language progresses. Parents, family members, and early childhood experts have a significant role in developing and maintaining the first Language. Researches show that knowing one Language can support the child to understand how other languages work. First or home language is chiefly vital for the child's development of a positive selfconcept and well-being.

They can offer opportunities for children to utilize their mother tongue in early childhood settings and at school and encourage the parents to use the mother tongue at home to provide a good foundation for learning English. It is imperative to reassure parents that children will learn English as a second language from English speakers ${ }^{[37]}$. The mother tongue opens the gate, including its grammar, to all grammars, in which it awakens the probability for general grammar that lies within all of us. It is the valued asset people bring to the task of language education. For this motive, the mother tongue is the chief key to foreign languages. This instrument gives us the fastest, surest, most precise, and most comprehensive tools of accessing a foreign language.

Successful learners capitalize on the vast amount of linguistic skills and world knowledge they have amassed thru the mother tongue. For the novice, becoming conscious of meanings automatically includes connecting them with the mother tongue - until the FL has recognized an ever-more multifaceted system for itself. The foreign language student must form upon existing skills and knowledge learned in and through the mother tongue. Monolingual topics without the mother tongue's aid are extrinsically possible; nevertheless, monolingual learning is an intrinsic impossibility.

No one can just turn off what they already recognize. It assumed that the mother tongue is 'silently 'present in beginners, even when lessons are kept monolingual. As we form our skills to vocalize, read, and write, all have been established via mother tongue, so we are incapable of switching off knowledge of the world acquired through the mother tongue. With the advent of research into the role of form-focused teaching, teacherresearchers have also begun to allow the mother tongue as a simple tool with the possibility to facilitate learning chiefly in accuracy-based tasks (Ferrer). "You can banish the MT from the classroom, but you cannot banish it from the pupils' heads" ${ }^{[43]}$. 
The connection between languages should be recognized and not ignored or suppressed. The non-use of the MT, but seriously compels what can be said and read. MT will save students from a feeling of frustration, which will eventually lead them to avoid all topics of particular interest. The mother tongue's measured and wellcalculated contribution can permit pupils to tackle more challenging texts sooner ${ }^{[38]}$.

\section{Cambodia}

The Cambodian Constitution of 1993 provides equal rights and opportunities for all Cambodian citizens to receive formal primary education.

In December 2007, the Cambodian National Assembly adopted a new Education Law. Article 24 of the Law states that: "The Khmer language shall be the Language of instruction, and a subject of the core curriculum used for general education in public schools. Private, general-education schools must have the Khmer language as a subject in their curriculum. The Language utilized by Cambodian learners of minority origin shall be determined by the Prakas of ministries responsible for education" [47]

In 2006, the Ministry of Rural Development crafted a National Policy on the Development of Ethnic Minorities, some of which relate to education. For example, it stated that human resource development should conform to the real interests and wishes of the minority peoples. It was deemed a priority that literacy programs and non-formal education should be organized to support the local knowledge, cultures, and languages of ethnic minorities. Language textbooks should be bilingual (in both Khmer and the relevant minority language), and orthographies for ethnic minority languages should be created based on the Khmer script ${ }^{[46]}$.

As one of the Collective Committee of the Dakar Framework for Action in 2000, the Royal Government of Cambodia dispensed Sub-Decree (Anukret) No. 84 ANK. On August 27, 2001, BK. was on creating the National Committee of Education for All ${ }^{[48]}$.

The EFA Committee is composed of the representatives of the Ministry of Education, Youth, and Sport (MoEYS), the Ministry of Interior, the Ministry of Economy and Finance, the Ministry of Planning, the Council of Ministers, the Ministry of National Defence, the Ministry of Rural Development, the Ministry of Women's and Veterans' Affairs, the Ministry of Health, the Ministry of Agriculture, Forestry, and Fisheries, the Ministry of Social Affairs, the Ministry of Culture and Fine Arts, the Ministry of Information, the Ministry of Religion and Cults, and the representatives of the Development Council of Cambodia. The Committee's mission is to develop 'Education for All' strategies and to draft policies and regulations that support and facilitate the implementation of 'Education for All' in Cambodia. The sub-decree also advised the Committee to seek cooperation from communities, local and international NGOs, civil society, and the private sector ${ }^{[49]}$.

In 2004, the Pedagogic Research Department of the MoEYS developed its Policy for Curriculum Development 2005-2009.

The MoEYS established an Office of Special Education in the Department of Primary Education. The office must provide equal education to disabled children and ethnolinguistic minority groups ${ }^{[50]}$.

Language plays an essential role in society. Through Language, people come to know their nation's civilization and culture, identity, and rhythms of their daily lives.

Providing language education to non-Khmerspeaking ethnic minorities in some remote areas of Cambodia is a priority of the Royal Government of Cambodia. To achieve this objective, the Government sees into all conceivable ways to aid ethnic minorities. For instance, this is done by constructing community schools, where ethnolinguistic minority children can learn their mother tongues first, after which they learn to speak, read, and write Khmer. Besides, literacy classes are established, and ethnolinguistic minority people are encouraged to attend them. School-aged ethnolinguistic minority children are also encouraged to attend community schools. Furthermore, the Government collaborates with international NGOs in orthography development for minority languages and establishes literacy classes in minority communities ${ }^{[47]}$.

The MoEYS of Cambodia, by a memorandum of understanding, authorized International Co-operation Cambodia (ICC) and Care International in Cambodia to organize educational projects in the northeastern provinces of Mondulkiri and Rattanakiri, in 2002 and 2003, respectively, where ethnic minorities such as the Bunong, Tampuan, Krueng, Brao and Kravet peoples constitute a substantial part of the population. The objectives of the projects are:

- To encourage the teaching of Khmer literacy and numeracy in ethnic communities of the Northeast. These activities could extend to some western provinces.

- To push for orthography development in ethnolinguistic minority languages based on the Khmer script, including linguistic and anthropological research into other ethnolinguistic groups to develop orthographies. 
- To pilot the creation of literacy classes in other provinces.

- To utilize materials and methods of non-formal education to instruct and train minority people.

- To add experience and techniques aiming to attain the goal of education for all.

Particular attention paid to those who cannot speak Khmer and live in remote areas. The aim is to include them in the Royal Government of Cambodia's 'Education for All' and encourage them to discuss bilingual education's effectiveness and implementation ${ }^{[47]}$.

\section{Analysis:}

In the implementation of the MTB-MLE, aside from the desire to address the indigenous people's needs, the Philippines and the Royal Government of Cambodia are committed to Education For All (EFA) and in reaching the Millennium Development Goals (MDG).

The EFA goals of aim to meet the learning needs of all children, youth, and adults by 2015 , such as:

1. Expanding and improving comprehensive early childhood care and education;

2. Have access, complete, free and compulsory primary education of satisfactory quality;

3. Equitable access to appropriate learning and lifeskills programs;

4. Achieving a 50 percent improvement in levels of adult literacy by 2015 , especially for women;

5. Eliminating gender disparities in primary and secondary education by 2005, and achieving gender equality in education by 2015 ; and

6. Improving all aspects of the quality of teaching and ensuring excellence of all

While the MDGs goals identified are:

Goal 2: Achieve universal primary education,

Goal 3: Promote gender equality and empower women and

Goal 4: Reduce child mortality

Besides, Mother Tongue-Based Language Education in the Philippines is meant to resolve Filipinos' high functional illiteracy, where Language plays an essential factor. Since the child's Language permits her/ him to easily express him/herself, there is no fear of making errors. It inspires the active contribution in the learning process because they can comprehend what is discussed and what is asked of them. They can instantly use their mother tongue to construct and explain their world, articulate their thoughts, and add new concepts to what they already recognize. While in Cambodia, it is a way to implement indigenous people's rights under the constitution in the education law and enforce United Nations treaties regarding indigenous people. In comparison, both countries implemented the MTB-MLE to preserve the indigenous languages and cultures and reduce poverty among indigenous communities.

\section{B. Target Learners of the MTB-MLE}

Principally, MTB-MLE targets learners who struggle to understand other languages rather than their Language, which is their first Language. Most of these learners are mostly entering Kindergarten and the first three years of grade school. Commonly, children will lose interest in going to school once they don't understand their school lessons. Since their parents are from diverse places around the state or the world, it's expected that they will express verbally and comprehend what they learn from their parents. Not all students can recognize English or other languages. At the start of classes, several will have difficulty handling the lessons since they're having difficulty understanding what the teachers are saying.

\section{Philippines}

The target learners are Kindergarten, grade 1, 2, and 3 pupils. The instruction, teaching materials, and assessment are in the regional or native Language of the students. The Department of Education (DepED) will implement a mother language transition program from Grade 4 to Grade 6 so that Filipino and English will be progressively introduced as languages of instruction until such time when these two (2) languages can become the primary languages of teaching at the secondary level.

A.

\section{Cambodia}

The target learners of Mother Tongue-Based Language Education in Cambodia are the indigenous individuals, mostly in the Northeast of Cambodia and certain parts of the country. These groups are the chief priority because they are the neediest. Also, indigenous languages with accepted orthographies, and the other minorities (Chinese, Vietnamese, Lao, and Cham have a script).

$B$.

\section{Analysis:}

In the Philippines, the target learners are the students from Kindergarten up to the first three years of elementary education. The instruction, teaching materials, and assessment are all in the learners' regional or native Language. While in Cambodia, the target learners are indigenous people from the Northeast of Cambodia and certain parts of the country. These groups are the chief 
priority because they are the most impoverished and other minorities (Chinese, Vietnamese, Lao, and Cham have a script).

In comparison, the MTB-MLE is implemented countrywide in the Philippines. It became a part of the primary education from Kindergarten to grade 3 . In Cambodia, the MTB-MLE is only implemented in the identified features, such as the areas where the indigenous groups are mainly situated and other ethnic minorities.

\section{A Closer Look at Community-Based Education (APC) in the Philippines and Identity Based Community Development and Education Programme (iBCDE ) in Cambodia}

\section{Philippines}

In the late 1980s, the nearby public school to Bendum was three hours away on foot: a walk too long and unsafe for school children. The community eagerly donated its resources towards the formation of an education program. They constructed a classroom in the hopes that the government would send them a teacher. At that time, essential services were inadequate, and there seemed to be no probable for government support.

In 1992, the community started working with an external support group. A sequence of community consultations undertaken in SitioBendum. The organization highlighted the need for education, but there was also a range of interrelated concerns raised: water and health, rattan and timber extraction, the security of their ancestral domain or gaup, abaca production, peace, and stability.

By 1993, a basic literacy program (reading, writing, and arithmetic) for children and adults was in SitioBendum. These classes were conducted in Pulangiyen, the mother tongue, because the community wanted an education that will give their children skills that would be useful and applicable to life in the community [51].

This cultural education program later developed into a formal school structure with a defined plan of education and learning system, including Filipino and English teaching. The assisting organization and community members designed a five-year education program that covered not only elementary level learning competencies but also integrated local culture and addresses expressed community needs. In 1995, the set-up was formal in that there was a full curriculum and a class schedule and system of record keeping. Still, there was no official recognition from the Department of Education (DepED).
This set-up presented a problem. The government did not officially recognize Indigenous Peoples' education initiatives, even if formal. Upon completing the cultural education program, the government required the students from Bendum to validate their education by taking equivalency examinations, the Philippine Educational Placement Test (PEPT), administered by DepED. This was a system developed by DepED, but there were limits to its application and accessing the system proved to be a further setback for many.

Although the PEPT worked well for lowland students, it did not respond to communities' realities in the uplands. The system left the Bendum students continuously detained at the primary level, unable to advance to secondary education. The community in Bendum, together with the assisting organization, decided that the best way forward was to obtain DepED recognition as an elementary school for Indigenous Peoples. They began this process in 2004.

The community named the school ApuPalamguwan Cultural Education Center (APC) after their mythical ancestor who embodied the community's desire to be educated in the context of their culture and way of life.

The ApuPalamguwan Cultural Education Center (APC) is a Jesuit-run, DepED-recognized elementary school for indigenous children settled in the Pantaron Range mountains, in the Bukidnon-Agusan border. APC is situated in a small indigenous village of 60 families called SitioBendum, Barangay Busdi, Malaybalay City. Bendum is a four-hour bus ride and a 30-minute motorcycle trip away from downtown. Working at the Frontiers: Educating Indigenous Children within the Context of their Culture Malaybalay. This school is a work of partnership with the Pulangiyen people of Bendum. The Pulangiyen is one of Bukidnon's indigenous groups, and as traditional, they recognize themselves by the river system that they reside in, the Pulangi River.

The APC School attends 120 children in Bendum and 60 more in an extension school nearSitioNabawang, a Pulangiyen village. Children from communities further away also learn at APC in Bendum and are accommodated in a school complex. APC teachers typically come from the Bendum community and are, therefore, Pulangiyen.

Lately, APC has started to establish classes in other small communities far away from public schools. The effort is to answer the need for education in these indigenous communities that are not reached by government services.

Right from the start, sessions in Bendum were taught in the mother tongue. At first, this was because the 
community desired their children to learn a practical literacy and numeracy that would be valuable for community life. Later, as the community's engagement settled, the people of Bendum began to eloquent the value they place on cultural individuality and saw the school's use of the mother tongue and its teaching of cultural knowledge as essential to support this identity. It must be said that the Pulangiyenindividuality is a recently resurfaced identity.

In the past, the people of Bendumrecognized themselves humbly as lumad, a common term for indigenous peoples in Mindanao. Like other indigenous groups, they usually felt a sense of disgrace in being identified as lumad. They felt lesser against the Bisaya, migrants who came from the Visayas, seldom spoke in community meetings, which the Bisaya dominated, and shied away from lowlanders. They viewed their Language and culture as inferior to the immigrants' Language and culture and most Filipino society.

Historically, indigenous peoples preserved their cultural identity by declining to be integrated into the new social orders taken about by the Spanish and American colonists. However, denial to adapt meant being pushed to the suburbs and driven up to the mountains where they had to struggle with increasingly barren land, restricted access to health and education services, and on the whole, being relegated from the broader political and economic development

All these have given various indigenous groups in Mindanao a sense of inferiority and a view that their culture is outmoded and that their Language does not have worth. It is the same in Bendum. Through the years, because of the mother tongue's sustained use and the teaching of cultural knowledge in school, this sense of inferiority has progressively overturned. Because the mother tongue is utilized in school, the message that both adults and the young are getting is that the mother tongue is significant and is appreciated. Now, children and adults similarly speak the mother tongue proudly in the community. They now assume visitors and outsiders to study their Language, instead of obliging the latter by speaking Bisaya.

The society's cultural practices are also alive, instead of being demoted as lessons in Social Studies, and even cultural history passed on to the subsequent generation. Current years have seen a change from the generic lumad identity to a more specific and more reflective Pulangiyenindividuality. The youth of Bendum now proudly identify themselves as Pulangiyen, in contrast to the sense of shame in being recognized as a lumad only a generation ago. Some APC graduates who have gone down to study in the lowlands sometimes tell that "When we are in the lowlands, we do not have an identity. But when we're up here in Bendum, we have an identity. You have given us an identity."

In Science class, APC students associate their people's farming systems, which permit land to lie fallow for a few years and thus naturally recuperate its fertility, with those of the migrants', which involve permanent and intensive agriculture heavily on chemical fertilizers and pesticides. In Social Studies class, they learn the indigenous political system and relate this vis-à-vis the local government system such as the sitio and barangay. In the lower grades, young children heed to folktales, instead of Western fairy tales, and study the cultural tenets in these stories.

In all these, APC students acquire that there are ample knowledge and wisdom in their culture. They learn that not all knowledge derives from books and that their parents and the community's elders are vital foundations of knowledge. They know that their way of life is neither obsolete nor inferior. It is respected, not only because it is theirs and because it ties them to their forebears, but because it continues to be relevant as they grapple with the challenges their communities face today.

Thus, Pulangiyen youth accept that there is much wisdom in their culture, wisdom that responds even to today's trials. This is important because regular Philippine education and society are typically oriented towards the West. We learn Western principles in school and the media, and we begin to think that all responses and knowledge come from the West.

Culture-based education programs such as APC show us a wealth of knowledge and wisdom in local cultures and languages. Cultures grow and change over the centuries as people struggle with the questions of how to survive, live with others, and find joy and meaning in their lives.

Thus, local cultures contain the accumulated wisdom of our forebears, and it would do us good to mine them for knowledge as we grapple with the issues we face today ${ }^{[52]}$

\section{Cambodia}

Ratanakiri Province is situated in the mountainous northeast of Cambodia, bordering Viet Nam to the east and Laos to the north. The sparsely populated province has a current population of around 110,000 inhabitants. About ten percent of the populace lives in Ban Lung town, the provincial center, where inhabitants are mainly ethnic Khmer who has recently migrated from the lowlands. The Khmers mostly live in the larger towns, 
where they are prominent in business, trading, and government services. It has only been in the past fifteen years that government departments have had a Ratanakiri $^{[54]}$.

The indigenous highland groups residing in remote areas are marginalized and separated from mainstream society by their isolated geographic location and language barriers. There are six main ethnic minority groups: Tampuen, Kreung, Brou, Kavet, Kachok, and Jarai. Not much of their history has been recorded, though the languages' linguistic characteristics shed some light on their origins. Most of the groups belong to the Mon-Khmer language group. The exception is the Jarai language, classified as belonging to the Austronesian (MalayoPolynesian) group. At present, the Tampuen is the biggest ethnic group, making up an estimated $24 \%$ of Ratanakiri's population. Jarai is the second largest group, with $19 \%$. The Kreung constitutes around $17 \%{ }^{[55]}$.

The Ratanakiri and Mondulkiri provinces in northeast Cambodia are amongst the poorest regions in the country. They consist of semi-mountainous and mostly forested areas that have been sparsely populated historically and are relatively isolated from the rest of the country. The majority of the population made up of indigenous peoples, all of whom have a distinct language and belief system. The status of the indigenous peoples of northeast Cambodia can be described as marginalized and vulnerable. Traditionally, their livelihood has been based on rotational farming, fishing, hunting, and gathering wild produce from the forest supplementing their crops. Today, the indigenous peoples in Ratanakiri and Mondulkiriface dramatically change their environment and livelihood ${ }^{[56]}$.

People in rural Cambodia are highly vulnerable to climatic effects. Numerous environmental challenges, such as the loss of traditional livelihoods, deforestation, overfishing, and land alienation, have hampered indigenous peoples' everyday lives. Indeed, the Ratanakiri and Mondulkiri provinces are among the three most environmentally vulnerable regions throughout Southeast Asia. Due to the new challenges that have impacted their traditional way of life, they are under pressure to adapt and conform.

The majority of the indigenous people in Ratanakiri and Mondulkiri do not speak Khmer, Cambodia's national Language, and most of them are also illiterate. The state education system uses the Khmer language as a medium of instruction in schools, which has invariably disadvantaged the ethnic minority children in accessing education. Moreover, the Khmer language's exclusive use has effectively excluded minorities from gaining membership in Cambodian society because of who they are, resulting in the indigenous culture ${ }^{[58]}$.

The core approach of the Identity Based Community Development and Education Programme (iBCDE) program was to foster deep relationships with the local communities. Based on previous observations, ICC aimed to empower the indigenous communities to reflect on and take action concerning three interrelated parts of their lives. To this end, the three main themes of the iBCDE program were: 1) Culturally Relevant Education (CRE), 2) Improved Indigenous Livelihoods 3) Community Wellbeing ${ }^{[59]}$.

Meanwhile, the Ratanakiri and Moldulkiri regions have had low literacy rates, low school enrollments, and high dropout rates. Indigenous peoples in these regions have been deprived of the right to learn in their mother tongue and the concomitant cultural teaching and learning [56]. The aim of Culturally Relevant Education (CRE) is for indigenous people and their communities to understand the purpose of education and for them to take ownership of knowledge in their village. iBCDE applies a rights-based approach, with specific emphasis on the right to participate. The program is grounded on the assumption that indigenous people are motivated, committed, and have ownership of the projects built according to their plans ${ }^{[58]}$.

The iBCDE program has opened and supported MTB MLE literacy classes held by local community members. The key CRE actors are local volunteer teachers who are chosen by the village community. The preferred teachers originate from the indigenous target group, speak the indigenous Language, and are familiar with it. The MTB MLE classes are held in the evenings because local teachers perform daily work in cultivating their fields. However, the local community members contribute to local teachers' efforts by helping them in other ways.

Local teachers are crucial to the success of the endeavor as they apply effective MTB MLE methodology whereby learning experiences in the classroom are connected to indigenous children's experiences and daily life, and which celebrates the value of their own culture. Besides, local people have high confidence in the teacher when they are from their community. The education level is not very high among teachers because it is difficult to find indigenous people who can read and write in both the learners' mother tongue and Khmer. On the other hand, an essential aspect of iBCDE is the volunteer teachers' capacity-building through teacher-training courses.

The literacy classes have received technical assistance from local community members. They have formed various language committees that have had an essential role in the production of teaching and learning 
resources for the classes. They have also regularly contributed their knowledge and understanding to community activities such as editing and improving local books and documents, conducting research into the traditional culture, and collating the findings ${ }^{[60]}$.

MTB MLE classes have used a "decentralized" school calendar compatible with local farming seasons, which considers the indigenous culture and the indigenous peoples' ability to attend classes, particularly when it comes to adults. Most of the ICC's classes were held during the evenings when daily chores were completed. The learning materials were also drawn from indigenous culture and traditions, which worked in two ways. Firstly, learning was easier for the children when the topics were familiar and reflected their indigenous culture. For example, songs used at school as learning techniques were selected according to harvest season activities. Secondly, oral traditions predominated, which served to strengthen and preserve the indigenous cultures. Through the iBCDE classes, children have become actively engaged in class because teachers use their mother tongue. The children can relate new information to what they are already familiar with ${ }^{[56]}$.

The implementation of projects in Rattanakiri and Mondulkiri that use ethnic minority languages to help those minorities acquire the official Language, together with experiences from other countries that have used students' mother tongues in education, demonstrate that such an approach nurtures the learners' awareness in teaching and literacy in both the mother tongue and the national or official Language. Providing biliteracy and educational options for ethnic minorities in Cambodia may be an excellent way to increase their interest and education participation. It may well serve to promote academic quality and achieve education for all in Cambodia.

C.

\section{Analysis:}

On the impact of the Mother tongue-based multilingual education, it positively impacts learning outcomes of indigenous students in the Philippines and Cambodia. Children and adults not speaking the national Language at home can access education and build relations and solidarity between the various ethnic groups.

Indigenous communities can now preserve their mother tongue and maintain and develop their culture: community history, traditions, and legends. Since this MTB-MLE provided equal access to education, indigenous people will also benefit from economic development.

\section{Perceived Effects of the MTB-MLE} Advantages
In Mother Tongue-based Multilingual Education, students are taught over some time in their native Language, and English is treated as a second language, taught side by side. Only when the student is believed to have attained proficiency in the native Language can he master English quickly. Technically and merely speaking, multilingual education is an educational system that favors education in more than one Language. According to its proponents, this system's essential benefit is that a student from a non-English speaking background can quickly learn English, owing to his language development, in his native Language, and the English Language.

Isn't it good to be skillful in numerous languages? What problem does it make if a student is well familiar in English and his mother tongue? Moreover, a child exposed to many languages will be able to advance a better sense of appreciating many cultures and understanding societies. After all, now we're living in a universal world and so being multilingual is always an advantage in firms and commercial industries.

Added to these benefits, the child can effortlessly use his mother tongue language in groups, and he won't feel embarrassed about it. In case he just knows of one Language, he may face problems of reluctance in expressing himself. It is a form of education as the minority speakers can learn English even while strengthening their cultural bonds by being proficient in their mother tongue.

\section{Disadvantages}

1. Unsuccessful Effort at Incorporation into Society

Multilingual education is considered essential since it was supposed to help incorporate the children of immigrants and minorities into society. The multilingual education scheme required separate teachers and classrooms and believed in continuous integration into society by allowing children to receive education in their mother tongue language for three or more years. Advocates of a single medium of instruction contradict bilingual education since they believed that separate teachers and classrooms would broaden the already prevailing gap between citizens and immigrants. They further suggested that inspiring children to interact within their community for three years would postpone the process of adjusting to the ways of life in a new state.

\section{School Dropout Rates}

Over the years, the dropout rate in many schools across North America has decreased significantly. The medium of instruction in the schools above is English. Nonetheless, there has been no decrease in the dropout 
rates for schools delivering multilingual education. The majority of people feel that a dropout rate of $35 \%$ doesn't validate the costs of providing this form of education.

\section{Unavailability of Teachers}

Multilingual education necessitates several skilled teachers who are expert in English and their mother tongue language, assuming that English is one of the mediums of instruction. There is a considerable gap between the demand and the supply for teachers, who are both selfassured and proficient in handling the intense pressure associated with managing students requiring special attention.

\section{Lack of Classrooms}

There is a shortage of classrooms that can accommodate students who need English instruction and their native Language. Students are anticipated to sit together in one class irrespective of their age and the differences in the required education level. This poses a great difficulty for teachers, who, in addition to being well-versed in two languages, have to simultaneously display a certain level of ease in handling different education levels.

\section{Lack of Funds}

The stated issue brings us to the tip of the problem: lack of funds to promote multilingual education.

\section{Bilingual Education is Costly}

Education becomes unavailable when a language that is not dominant is to be educated. The situation becomes economically possible when multiple languages are usually utilized are taught. An education system ought to be conscious that the noble sap of education and literacy lies in understanding the Language in which knowledge is communicated. The subject's content and context become unconscious if the student is not well conversant with the Language employed.

Furthermore, most mother tongue-based education in Southeast Asia occurs in the non-formal sector, particularly at the preschool or adult literacy classes. Most programs run by non-governmental actors, such as local and international NGOs and other civil society actors. In some cases, such endeavors have become part of the national system of education. Notwithstanding many challenges, pilot projects using non-dominant languages as media of instruction and literacy in government systems are commencing or ongoing in several Southeast Asian countries. Nonetheless, it is significant to note that the use of non-dominant languages in SEAMEO countries is still mostly at a preliminary stage. Current pilot projects are relatively small in scope. Oral use of NDL (Non-Dominant Languages) in education seems shared in many minority areas where teachers share the Language with their students.

\section{Analysis:}

MTB-MLE was a new concept for Cambodia, and government officials and indigenous communities were not clear about MLE's purpose. There are many languages (19) that still need orthographies. While in the Philippines, many Filipinos believe that using English as a language of instruction in formal primary education will make children proficient in that Language even though it is not the first Language of most Filipinos.

In comparison, both countries have problems with the limited human resources in the indigenous areas and the lack of teaching materials and culturally relevant textbooks. There is also limited budget and financing arrangements and a problem in sustaining community support.

\section{CONCLUSION}

It had been witnessed that in almost all the countries, the indigenous people are taken for granted. If not obliged, they are anticipated to assimilate to the sociopolitical edifices, social practices, and the social standards that are mostly built by the majority. Even then, the majority still treats them as less than equal, if not less than human. Regarding the minority in the language aspect in the Philippines and Cambodia, this learning initiative is ideal for the schools that cater to disabled students and students who have special needs. The new program, which is the MTB- MLE, is most likely to enhance and help them make meaning to the concepts and topics introduced. There would be no concern in understanding the idea since they already understand the Language used in teaching the content, making it easier for them to make it personal and relevant.

Since mainstreaming aims to allow students with special needs to learn at par with regular students, this learning initiative would augment that aim. It would fully engage students with special needs in the "regular world." It would also put them at par with the reality that regular students are in. This learning initiative would aid these marginalized minorities through supporting the usage of their mother tongue and assisting them in making sense of the words and the world they are in.

In line with the prominent features of this MTBMLE learning initiative, this would be powerful in developing their language literacy, thus providing them with a strong educational foundation on their first Language and bridging it in learning another language other than their official languages and the English 
Language. It will also enable them to utilize both or all languages in their own choice. Given that students with special needs find it thought-provoking in transferring concepts and immediately making meaning on concepts compared to regular students, this learning initiative would put their mother tongue as their solid foundation in figuring out the importance of each topic, and the idea introduced, making it less stressful and difficult.

In the aspect of social development, since these minorities have difficulty with respects to their social skills, this learning initiative would enable them to make it less threatening for them to engage themselves in social circles, practices, and activities, may it be joining a person or two in the playground and engaging in a simple play or social gathering. MTB- MLE allows these students to use their recognized culture and permitting them to comprehend social practices instantly, activities, and realities based on their known world outside those in school-their known world at home, inspiring them to interact and share what they usually do at home since the Language used at home, is the same Language used in school.

And the last salient feature of MTB- MLE students with special needs can make sense of what the teacher is saying since the Language used is their mother tongue, which they most likely utilize at home and are accustomed to. It would also permit this minority to be well prepared to attain well in the mainstream education system as most parents aim their children to achieve. The learning experience of learners with special needs would most likely be enhanced with this learning initiative. It is grounding the acquisition of concepts, topics, context, and ideas in their known Language and permitting immediate acceptance to these concepts since the Language used is already an experienced everyday activity. It would limit special needs students' intimidation, threat, and hesitation in participating socially, academically, and emotionally since they could see that their fellow students and teachers are using the same known Language regarding teaching and learning. It placed them on the same standard as the other regular students, letting them feel the difference between traditional students and special needs students.

This learning initiative would most likely inspire students to achieve more by not making big concepts in different subjects intimidating since the Language used are non- threatening to them. This would permit them to relate their everyday reality to reality nationally, internationally, and globally. Upon having a solid foundation on their mother tongue, students can preserve their local individuality and national identity, thus giving them a key to fully experience the world outside their known world through the world wide web, media, and global activities.
This learning initiative is ideal for the marginalized minority. It poses a challenge to its proponents, especially the teachers, since being the old education system product, which uses English as the medium of instruction. Teachers may find a constant challenge to cultivate their known mother tongue and use it in their teaching practices. Learning once again how to write in their mother tongue simultaneously is critical with the syntax and technicalities. When it comes to grammar in the mother tongue, one could not directly translate English sentences to one's mother tongue due to its arrangement and syntax.

Teachers have to change what they have known, used, and practiced in their education and profession. It is a shift to teaching. Utilizing their mother tongue and integrating it to their instruction; it would mean relearning terminologies and changes in outlines, instructional materials, resources, references, educational strategies, and practices. These challenges are to be faced head-on and demands consistency and result from stakeholders such as schools, parents, students, and the government.

This learning initiative's successful practice would bring about better understanding students, better learners, improvement of higher-order thinking skills, life skills, and whole-rounded learners. It would also endorse unity in diverse localities in the same region, harmony in schools, and not having that glaring difference in status basing on the Language spoken, unity in public and private school sectors, unity and uniformity in concepts taught.

\section{RECOMMENDATIONS}

1. Solid and well-planned MT-Based MLE programs aid students in building a robust educational basis. It inspires students to develop verbal fluency. It presents reading and writing in their first Language, supports students in becoming fluent and self-assured, and builds capacity to utilize their mother tongue for daily communication.

2. The government could make a periodic assessment of the policy to see whether it is fulfilling its purpose.

3. The government could examine the nation's top priorities and implement a language-in-education policy that will address these needs.

\section{ACKNOWLEDGEMENTS}

I want to acknowledge the Kalinga State University for giving me the opportunity and sufficient 
support in order for me to be able to successfully conduct this research.

\section{REFERENCES}

[1] United Nations. (, 2007). Declaration on the Rights of Indigenous Peoples (Adopted by General Assembly Resolution 61/295 on September 13, 2007) Retrieved September 2, 2013, from http://www.un.org/esa/socdev/unpfii//en/drip.html.

[2] UN 2008: United Nations Declaration on the Rights of Indigenous Peoples. Retrieved from http://www.un.org/esa/socdev/unpfii/ documents/DRIPS_en.pdf.

[3] Kosonen, Kimmo, \& Person, Kirk R. (2013). Languages, identities, and education in Thailand. In Peter Sercombe \&RuanniTupas (Eds.), Language, identities, and education in Asia. Palgrave Macmillan. Forthcoming.

[4] Thomason, S. (2015). Endangered Languages: An Introduction (Cambridge Textbooks in Linguistics). Cambridge: Cambridge University Press. DOI:10.1017/CBO9781139033817

[5] UNESCO 2016: International Mother Language Day 2016. Retrieved from http://en.unesco.org/events/ internationalmother-language-day-2016.

[6] D'Emilio, A. L. 2009: Indigenous Languages: A View from UNICEF. State of the World's Minorities and Indigenous Peoples 2009.Exclusive online material. Retrieved from http://minorityrights.org/wp-content/uploads/old-sitedownloads/download-66 4-Online-ExclusiveIndigenousLanguages-a-view-from-UNICEF.pdf.

[7] Pinnock, H. \&Vijayakumar, G. 2009: Language and education: the missing link. How the Language used in schools threatens the achievement of Education For All. Education Trust \& Save the Children. Retrieved from http://www.unesco.org/educatio n/EFAWG2009/LanguageEducation.pdf.

[8] Smits, J., Huisman, J. \&Kruijff, K. 2008: Home language and education in the developing world. Commissioned study for EFA Global Monitoring Report 2009. UNESCO. Retrieved from http://unesdoc. unesco.org/images/0017/001787/178702e.pdf.

[9] Bialystok, E., Peets, K., and Moreno, S. 2014: Producing bilinguals through immersion education: Development of metalinguistic awareness. Applied Psycholinguistics. Volume 35, Issue 1, January 2014, pp. 177-191.

[10] UNESCO 2016: International Mother Language Day 2016. Retrieved from http://en.unesco.org/events/ internationalmother-language-day-2016.

[11] Kosonen, K. 2017: Language Policy and Education in Southeast Asia. In Teresa McCarty \& Stephen May (Eds.) "Language Policy and Political Issues in Education," Chapter 35, Vol. 1 of Stephen May (Ed.) Encyclopedia of
Language and Education, 3rd edition. New York: Springer. DOI 10.1007/978-3-319-02320-5_35-1.

[12] Kosonen, K. \& Young, C. (eds) 2009: Mother Tongue as a Bridge Language of Instruction: Policies and Experiences in Southeast Asia. Bangkok: Southeast Asian Ministers of Education Organization (SEAMEO).

[13] Kosonen, K. 2005: Education in local languages: Policy and practice in Southeast Asia. First languages first: Community-based literacy programmes for minority language contexts in Asia. Bangkok: UNESCO Asia and Pacific Regional Bureau for Education, Bangkok. Retrieved fromhttp://www.literacyportal.net/china/resources/manuals/ English/010/firstLanguageFirst.pdf \#page=96.

[14] UNESCO 2005: First Language First: Community-based Literacy Programs for Minority Language Contexts in Asia. http://unesdoc.unesco.org/images/0014/001402/140280e.pd f.

[15] Benson, C. 2002: Real and potential benefits of bilingual programmes in developing countries. International Journal of Bilingual Education and Bilingualism, 5 (6).

[16] UNESCO 2007: Promoting Literacy in Multilingual Settings. Bangkok. ISBN 92-9223-100-6.Retrieved from http://unesdoc.unesco.org/images/0015/001507/150704e.pd f.

[17] Benson, C. 2005: Mother Tongue-based Teaching and Education for Girls. Bangkok, UNESCO. Retrieved from http://unesdoc. unesco.org/images/0014/001420/142079e.pdf.

[18] Indigenous People's Education. https://www.hurights.or.jp/archives/pdf/asia-sed/v11/13Indigenous\%20Peoples\%20Education \%20Philippines.pdf. Date accessed: 01/05/2019. $\% 20-$

[19] The People and Language of Cambodia. https://www.asiahighlights.com/cambodia/people-andlanguage.htm Date accessed: 01/05/2019.

[20] Ethnologue Languages of the World: Philippines. https://www.ethnologue.com/country/18-165 Date accessed: 06/05/2019.

[21] Mother Tongue Based Education in the Philippines.https://www.culturalsurvival.org/news/mothertongue-based-education-philippines Date accessed: 06/05/2019.

[22] Kosonen, Kimmo (2009b). Language-in-education policies in Southeast Asia: An overview. In KimmoKosonen\& Catherine Young (Eds.), Mother tongue as bridge language of instruction: Policies and experiences in Southeast Asia (pp. 22-43). Bangkok: Southeast Asian Ministers of Education Organization (SEAMEO).

[23] Kosonen, Kimmo (2007). Vernaculars in literacy and basic education in Cambodia, Laos, and Thailand. In Anthony J. Liddicoat (Ed.), Issues in language planning and literacy (pp. 122-142). Clevedon, UK: Multilingual Matters.

[24] Kosonen, Kimmo (2010). Ethnolinguistic minorities and non-dominant languages in mainland Southeast Asian 
language-in-education policies. In A. M. Geo-JaJa\& S. Majhanovich (Eds.), Education, Language, and economics: Growing national and global dilemmas (pp. 73-88). Rotterdam/Boston/Taipei: Sense Publishers.

[25] Benson, C. 2011: Evaluation of the state of bilingual education in Cambodia.

[26] Benson, Carol, \&Kosonen, Kimmo (2012). A critical comparison of language-in-education policy and practice in four Southeast Asian countries and Ethiopia. In Kathleen Heugh\&ToveSkutnabbKangas (Eds.), Multilingual education and sustainable diversity work: From periphery to center (pp. 111-137). New York: Routledge.

[27] Neou Sun (2009). Education policies for ethnic minorities in Cambodia. In KimmoKosonen\& Catherine Young (Eds.), Mother tongue as bridge language of instruction: Policies and experiences in Southeast Asia (pp. 62-68). Bangkok: SEAMEO.

[28] Noorlander, Jan, \&Ven, Churk (2008). Cambodia's highland community education program. A paper presented at the Second International Conference on Language Development, Language Revitalization, and Multilingual Education in Ethnolinguistic Communities. Bangkok, 1-3 July 2008 .

[29] UNESCO (2007b). Mother tongue-based literacy programmes: Case studies of good practice in Asia. Bangkok: UNESCO Asia and Pacific Regional Bureau for Education.

[30] Basic Education Sector Reform Agenda (BESRA), 2010. BESRA Key Reform Thrust 3: Influential social institutions and key social processes are engaged by DepED to support national scale attainment of desired learning outcomes. Retrieved from http://www.fnf.org.ph/downloadables/Basic\%20Education $\% 20$ Sector\%20Reform\%20Ag enda.pdf

[31] Dekker, D.E. and Dumatog, R. (2004) First language education in Lubuagan, Kalinga, northern Philippines. Paper presented at the Conference on Language Development, Language Revitalization, and Multilingual Education in Minority Communities in Asia, Bangkok, Thailand. On WWW, at http://www.sil.org/asia/ldc/ parrallel_papers/dumatog_and_dekker.pdf.

[32] Young, C. (2002) First Language first: Literacy education for the future in a multilingual Philippine society. International Journal of Bilingual Education and Bilingualism 5 (4), 221-32

[33] CHED K to 12 Transition Program. https://ched.gov.ph/k12-project-management-unit/. Date accessed: 06/05/2019.

[34] Bredenburg, Kurt (2010). Assessment of Cham and migrant children's educational needs in Cambodia. A paper presented at the International Conference on Language, Education, and the Millennium Development Goals, November 9-11, 2010, Bangkok, Thailand. (http://www.seameo.org/LanguageMDGConference2010/d oc/presentations/day1/KurtBredenberg-ppt.pdf)
[35] Benson, C., \&Kosonen, K., 2013: Language Issues in Comparative Education. Inclusive Teaching and Learning in Non-Dominant Languages and Cultures. Sense Publisher. Rotterdam / Boston / Taipei. Retrieved fromhttps://www.sensepublishers.com/media/ 1624language-issues-in-comparative-education.pdf

[36] Mother Tongue-Based Language Education. https://www.cu.edu.ph/?page_id=3290. Date Accessed: 06/05/2019.

[37] Clarke, P. M. (2009). Supporting children learning English as a second language in the early years (birth to six years) (p. 8). VCAA.

[38] Hassanzadeh, N., \&Nabifar, N. (2011). The effect of awareness and explicit knowledge of mother tongue grammar on the learning of foreign language grammar. Journal of Academic and Applied Studies, 1(2), 7-24.

[39] DepEd develops learning supplements using the mother tongue.

https://www.officialgazette.gov.ph/2011/11/28/deped-

develops-lear ning-supplements-using-mother-tongue/. Date Accessed: 02/06/2019.

[40] Malone, S. (2007, September). Mother tongue-based multilingual education: Implications for education policy. In Seminar on Education Policy and the Right to Education: Towards More Equitable Outcomes for South Asia's Children (2007 Kathmandu).

[41] Cummins J. The role of primary language development in promoting educational success for language minority students. In: California State Department of Education, editor. Schooling and language minority students: A theoretical framework. Evaluation, Dissemination, and Assessment Center, California State University; Los Angeles: 1981. pp. 3-49.

[42] Cummins J. Interdependence of first- and second-language proficiency in bilingual children. In: Bialystok E, editor. Language processing in bilingual children. Cambridge: Cambridge University Press; 1991. pp. 70-89.

[43] Butzkamm, W. (2007). Native language skills as a foundation for foreign language learning, Wolf Kindermann (ed.), Transcending Boundaries.Essays in honour of Gisela Hermann-Brennecke.

[44] Butzkamm, W. (2003). We only learn a language once. The role of the mother tongue in FL classrooms: the death of a dogma. Language learning journal, 28(1), 29-39.

[45] NOLASCO, R. M. D. (21). 21 Reasons why Filipino children learn better while using their Mother Tongue.

[46] Kheang, T., O'Donoghue, T., \& Clarke, S. (2018). Primary School Leadership in Cambodia: Context-Bound Teaching and Leading. Springer.

[47] Sun, N. (2009). Education policies for ethnic minorities in Cambodia. Mother tongue as bridge language of instruction: Policies and experiences in Southeast Asia, 6268 . 
[48] UNESCO, P. (2000). The Dakar framework for action.The World Declaration on Education.

[49] Pellini, A. (2007). Decentralization policy in Cambodia: Exploring community participation in the education sector. Tampere University Press.

[50] Sovachana, P. (1991). Progress and challenges of education in Cambodia today. Cambodia progress and challenges since, 292-319.

[51] Cornelio, J. S., \& de Castro, D. F. T. (2016). The state of indigenous education in the Philippines today. In Indigenous culture, education and globalization (pp. 159179). Springer, Berlin, Heidelberg.

[52] APC. (, 2012). Apupalamguwan cultural education center: Culture-based education in a community school. Department of Education (Indigenous Peoples Education Office): Pasig City.

[53] Asian Development Bank. Environment \& Social Safeguard Division. (, 2002). Indigenous Peoples/Ethnic Minorities and Poverty Reduction, Cambodia (Vol. 1). Asian Development Bank.

[54] Middleborg, J. (2005). Highland Children's Education Project: A Pilot Project on Bilingual Education in Cambodia.

[55] CARE 2003, The Highland Children's Education Project, Base Line Study. 2003. CARE Cambodia, Phnom Penh.

[56] Felm 2013: Project Plan - Development Cooperation. Ratanakiri and Mondulkiri Provinces.Unpublished internal document.

[57] ICC 2014: Identity-Based Community Development and Education. Unpublished internal document.

[58] ICC 2013: iBCDE Project Report Format. Unpublished internal document.

[59] Sandberg, A. (2017). Mother Tongue-Based Multilingual Education among Linguistic Minorities. Indira Helsinki.

[60] ICC 2016: ICC iBCDEProgramme Report. Unpublished internal document.

[61] Burton, L. A. (2013). Mother tongue-based multilingual education in the Philippines: studying a top-down policy from the bottom up 